\title{
Spur and Helical Gear Sliding Loss Model with Load Distribution Pattern on Gear Tooth Surface
}

\author{
Natcha Ponchai, Jetsada Phraeknanthoe, and Chanat Ratanasumawong* \\ Department of Mechanical Engineering, Faculty of Engineering, Chulalongkorn University, \\ Phayathai Road, Patumwan, Bangkok 10330, Thailand \\ *E-mail: chanat.r@chula.ac.th (Corresponding author)
}

\begin{abstract}
The model for estimation of spur and helical gear sliding loss with load distribution pattern on gear tooth surface is presented in this paper. The load distribution for the spur gear is considered to distribute uniformly along the line of contact. During double teeth meshing, load sharing ratio between meshing teeth is considered to be 33:67 percent or $45: 55$ percent. For the helical gear the load distribution can be calculated by the method proposed by Niemann and Richter. The contour plots of load distribution on gear tooth surface conform to the tooth contact patterns obtained experimentally. The sliding losses estimated from the presented method are compared with the estimations done by the former model and also the experimental results. It is found that the sliding losses calculated from the presented method are closer to the experimental results than the estimations from the former model. The effects of the helix angle and pressure angle on the sliding loss can also be estimated correctly by the presented method.
\end{abstract}

Keywords: Spur gear, helical gear, sliding loss, load distribution.

ENGINEERING JOURNAL Volume 22 Issue 2

Received 28 June 2017

Accepted 7 February 2018

Published 30 March 2018

Online at http://www.engj.org/

DOI:10.4186/ej.2018.22.2.101 


\section{Introduction}

The demand of high efficiency gear is drastically increase nowadays due to increasing of the energy price and the severe competition in the market. Although the efficiency of a gear pair has been considered to be higher than the other power transmission methods, the use of multi-stages gear transmission especially in automobiles or in agricultural machines increases the power loss in the transmission considerably. Reduction of the power loss only a few percent possibly increase efficiency of the whole system significantly. Understanding of the mechanism of gear power loss makes it is possible to reduce the gear power loss in the design stage. Power losses in transmission gear attribute to many sources such as the sliding and rolling between gear tooth surface, the method of lubrication and air resistance or windage loss. For small gears operated at low or moderate speed such as the gear in automobiles or in the agricultural machines, the sliding loss is the dominant loss and be focused here.

There are many researches in the past focusing on the mechanism and the mathematical model to explain and assess the gear sliding loss. Michlin and Myunster [1] presented the simple gear meshing model to explain the sliding and rolling loss of a spur gear pair. Although their method is simple and easy to understand, there are many points that must be improved to increase the accuracy of estimation including the calculation during double teeth meshing and the value of coefficient of friction. In their paper the constant friction coefficient was used, but it has been known from the former researches [2-6] that the value of coefficient of friction is depended on the rotational speed, loading condition and also the viscosity of the lubricant. To improve the accuracy of the calculation, the accurate value of friction coefficient is required. There are two main methods to determine the friction coefficient in the sliding loss model. First is the use of empirical formula of friction coefficient in calculation. Some researches in this group are the works of Anderson and Lowenthal [7], Terauchi et al. [8] and the authors' former works [9, 10]. Another method is the use of Elastohydrodynamic Lubricant (EHL) model to determine the accurate friction coefficient. The samples of researches in this group are the works of Xu et al. [11] and Diab et al. [12]. Although the method base on the EHL model seems to give the satisfy results, it consumes large computational time and is still not suitable for practical application. On the contrary although the method based on the empirical formula of friction coefficient has some restrictions depended on the experimental conditions used to construct that formula, it is much simpler and more suitable to implement. Moreover in many reports [7-10], it is found that the satisfied sliding loss estimation is able to acquire by using the proper empirical formula, and hence the method based on the empirical formula is chosen to use in this paper.

In the authors' former work [9] the sliding loss model and the method used for estimation was proposed and it can be used quite well in almost conditions. However estimated results in some cases still do not agree with the experimental results [13]. The assumptions that the load is equally shared between gear teeth during double teeth meshing for the spur gear case and the load is uniformly distributed along the line of contact for the helical gear teeth are considered to be an important cause of the errors. If the data of the tooth contact pattern is obviously known, it can be used to improve the accuracy of the estimated results [14]. Unfortunately the data of tooth contact patterns cannot be obtained easily without many experimental supports, hence the used of actual contact pattern for sliding loss estimation is also impractical.

In this work, the effects of load sharing among gear teeth and load distribution on a gear tooth surface reported in the former research works are added into the former gear sliding loss model. The effectiveness of the improved model is verified by comparing the results with the experimental results and the results calculated from the former model. The results reported by another researcher are also used to verify the estimated sliding losses.

\section{Review of the Former Sliding Loss Model}

For better understanding of the proposed method, the main concepts of the former sliding loss model are briefly reviewed here. The details of the former model can be read from the ref. $[9,10]$.

The cause of gear sliding loss is the difference between the velocity vectors at the contact points on the driving and driven tooth that brings about sliding and friction on the gear tooth surface. The sliding loss $\mathrm{H}_{3}$ can be calculated by subtracting the output power $H_{2}$ from the input power $H_{1}$ as shown by equation 


$$
H_{3}=H_{1}-H_{2} .
$$

For the single tooth meshing spur gear, the sliding loss ratio $\varphi$ that is the ratio of the sliding loss and the input power at any meshing position can be calculated from

$$
\varphi=\frac{H_{3}}{H_{1}}=\frac{-n \cdot \tan \alpha \cdot \mu \cdot(1+m)}{1-(n+1) \cdot \tan \alpha \cdot \mu}
$$

where $n$ is the position ratio relevant to meshing position, $\alpha$ is the pressure angle, $\mu$ is the friction coefficient, and $m$ is the speed reduction ratio. The plot of sliding loss ratio calculated from Eq. (2) is shown by a V-graph in Fig. 1(a). The sliding loss ratio is large at the position close to the beginning of gear meshing and at the end of meshing where the sliding velocity is large. At the pitch point where the velocities of driving and driven gear are equal, the sliding loss ratio equals to zero.

In the actual operation, double teeth meshing occur at some periodic moments as shown by the areas that the V-graphs overlap in Fig. 1(a). With the assumption that the load distributed uniformly on the line of contact, the load is equally shared between tooth-pairs. The total sliding loss ratio in this situation can be calculated by directly averaging sliding loss ratio of both tooth pairs meshing at that time as shown by equation:

$$
\varphi_{\text {total }}=\frac{\varphi_{\mathrm{Z} 1}+\varphi_{\mathrm{Z} 2}}{2}
$$

where the subscripts Z1 and Z2 are the first and the second tooth pair, respectively. The variation of the sliding loss ratio along meshing position is shown in Fig. 1(b). The average value of total sliding loss ratio $\bar{\varphi}$ is also shown by the dash line in Fig. 1(b).

For the helical gear case, force acting on the helical gear tooth surface can be divided into the transverse component and the axial component. The axial component does not affect to the sliding loss due to zero displacement in the axial direction, hence only the transverse component is considered in the sliding loss calculation as same as in the spur gear case. With this reason the method used to determine the sliding loss ratio of the spur gear pair can also be applied to the helical gear pair. To estimate the sliding loss of a helical gear pair, the helical gear is modeled as many thin spur gears aligned slantwise along with the base helix angle as shown in Fig. 1(c).

The sliding loss ratio of single tooth pair of a helical gear pair is shown in Fig. 1(d). Each V-graph in the figure represents the sliding loss ratio of each spur gear section. Figures 1(e)-(f) show the sliding loss of the other tooth pairs meshing at that time. The total sliding loss ratio during multi-teeth meshing can be calculated by averaging the sliding loss ratio of the spur gear sections that synchronously mesh. For example, at time $t$ in Fig. 1(d)-(f) the sliding loss ratios of synchronously meshing sections are shown by position 1 to 10 aligned along the vertical line. As same as the spur gear case, the assumption that the force is distributed uniformly along the line of contact is used in the calculation. Figure $1(\mathrm{~g})$ shows the variation of sliding loss ratio during meshing and the dash line represents the average value of sliding loss ratio.

The model described in this topic will be improved by adding the effect of load sharing ratio and the load distribution along the line of contact that will be described in the further sections. 
Spur Gear

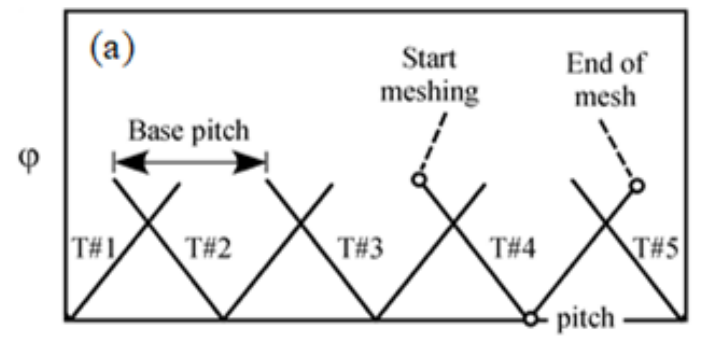

(b)

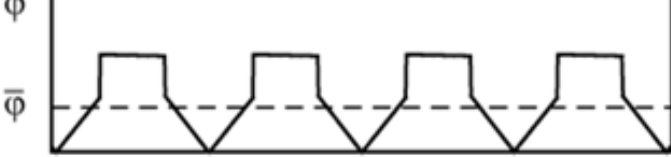

n

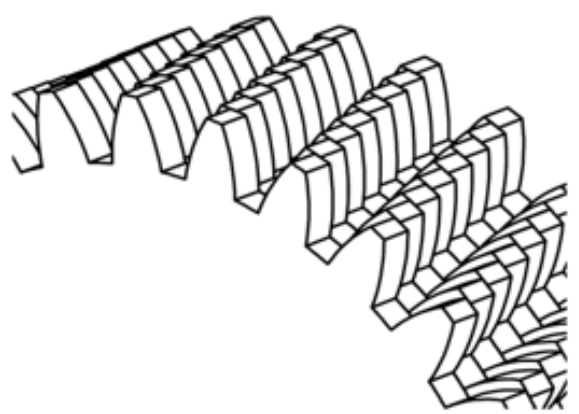

(c) Model of a helical gear
Helical Gear
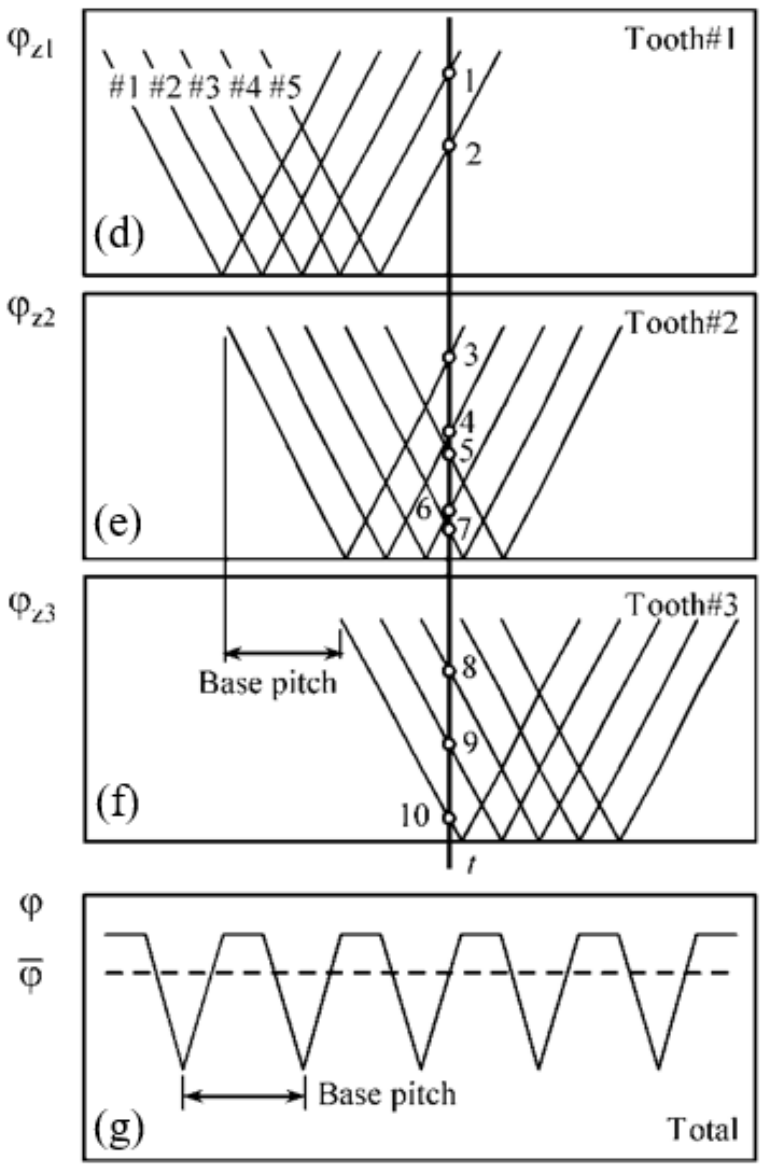

Meshing position

Fig. 1. Sliding loss ratio of a spur gear and a helical gear pair [9].

\section{Load Sharing and Load Distribution on the Gear Tooth Surface}

To investigate the load distribution on the gear tooth surface, some tooth contact experiments were done with the back-to-back gear test rig. The three-consecutive tooth surfaces were painted by red layout fluid. After operating at rotational speed $2000 \mathrm{rpm}$ and at specific torques for 6 minutes, the photos of tooth contact patterns were taken. Figure 2 shows the samples of tooth contact pattern of a spur and a helical gear. The area that the paint is peeled off represents the area in which the larger load is distributed. From the figure, the area that the paint is peeled off is located at the center of the tooth. This area enlarges to almost full tooth surface when the applied load is increased. This indicates that the large load is distributed at the center of both spur and helical gear.

For the spur gear, because single tooth meshing occurs at the area close to the pitch point, the load distribution at this area is larger than the area close to tooth tip or tooth root where double teeth are meshed, hence the paint is started to peel off from the center area of the tooth. Moreover with these tooth contact patterns, the assumption that the force is distributed uniformly along the line of contact is applicable, since the paint is uniformly peeled off along the line of contact parallel with the face width. However the load sharing ratio during double teeth meshing is still not known. 


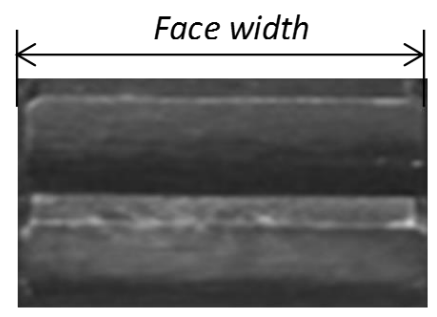

Painting before experiment

(a)

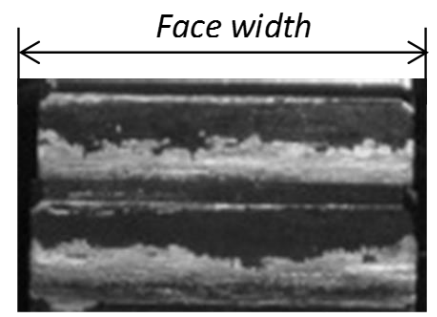

Experimental result

(Spurgear)

(b)

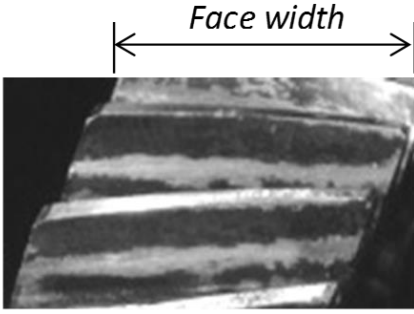

Experimental result (Helical gear)

(c)

Fig. 2. Samples of tooth contact patterns.

On the contrary, for the helical gear the former assumption that the force is distributed uniformly along the line of contact is inapplicable. This is because the contact lines of helical gear align slantwise relevant to the helix angle, if the force is uniformly distributed, the peel off area must be aligned at the same direction with the contact line. With this reason, to improve the accuracy of the sliding loss model, load sharing and load distribution are necessary to consider.

\subsection{Load Sharing Ratio of a Spur Gear Pair}

There are many researches reporting about the load sharing ratio of a spur gear pair. Some of them are the studies of J. I. Pedrero et al. [15], M. Ristivojević et al. [16], V. Spitas et al. [17] and S. Li et al. [18]. These researches determined the values of load sharing ratio with various methods including analytical method, experiment or finite element analysis. All of them found that the load sharing ratio during double teeth meshing is almost linearly varied along the meshing positions, but amounts of load sharing ratios reported in these researches are slightly different from 33:67 to nearly 50:50 percent. The variations of load sharing ratio along meshing position from these researches are shown in Fig. 3.

In this work, the load sharing ratio 33:67 and 45:55 percent are used in the sliding loss calculation. The assumption that the force is uniformly distributed along the line of contact is still used in calculation here. The newly calculated results are compared with the experimental results and the former calculation which the assumption that the load is equally sharing between meshing teeth (load sharing ratio 50:50 percent) is applied.

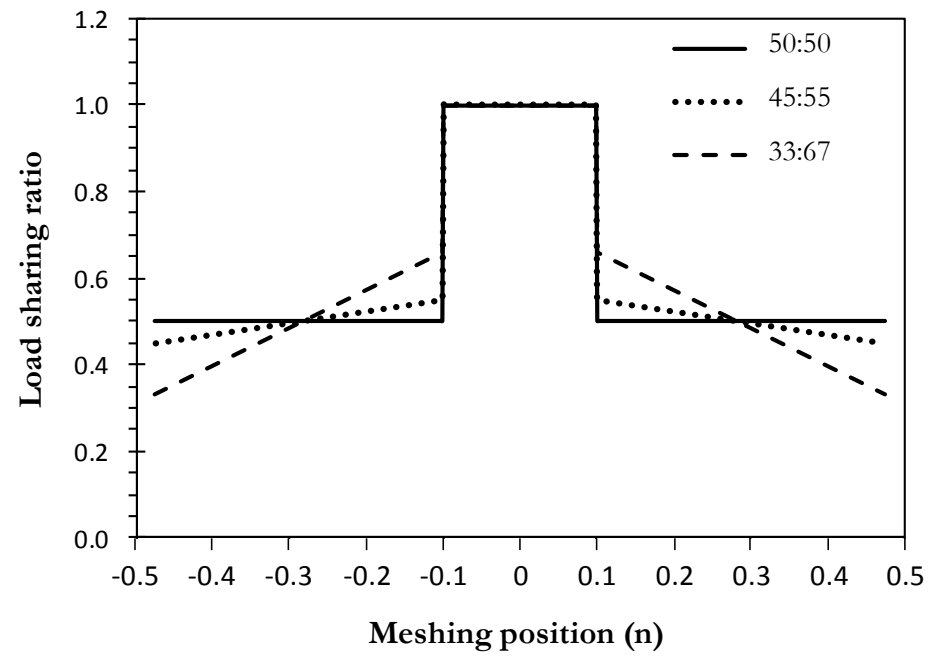

Fig. 3. Load sharing ratios at various meshing positions. 


\subsection{Load Distribution of a Helical Gear Pair}

The load distribution on helical gear tooth surfaces can be calculated by the method proposed by NiemannRichter [19]. The results calculated from this method agree well with the load distribution reported in the refs. [20,21]. This confirms ability in using this method to estimate the load distribution on the helical gear tooth surface. In the Niemann-Richter method, the load distribution at the various meshing positions can be written in the form of function $u(x)$ as shown by equation:

$$
u(x)=u_{m}\left(1+0.4 \cos \left(2 \beta_{g}\right) \cos (\pi x)\right)
$$

In Eq. (4), $\beta_{g}$ is the base helix angle. $x$ is normalized meshing position. $x$ equals zero at the middle of the meshing and equals -1 or 1 at the beginning or the ending of meshing position. $u_{m}$ is the mean load that can be calculated by

$$
u_{m}=U / b_{N}
$$

where $U$ is the tooth force when gear is meshing at the pitch point and can be calculated by dividing the applied torque by the pitch radius. $b_{N}$ is the projection of the total length of contact on the face width direction that can be expressed by equation

$$
b_{N} \quad=\sum l \cos \left(\beta_{g}\right) \text {, }
$$

where $l$ is the length of contact of a tooth pair meshing at that moment.

From Eq. (4), when the gear parameters and applied load are known, load distribution along the line of contact of any meshing tooth pair can be determined, that makes this method very convenient to apply in the sliding loss calculation.

\subsection{Contour Plots of Load Distribution on the Gear Tooth Surface}

Load distributions on the tooth surface calculated by the method described above are displayed by the contour plots and are compared to the photos of tooth contact pattern as shown in Figs. 4 and 5. The area having light color in the contour plot shows the area where the larger load is distributed, on the other hand the area having dark color relates to the low load distributing area.

Figure 4 shows the contact patterns of the spur gear pair having 30 teeth, module $3 \mathrm{~mm}$, pressure angle $20^{\circ}$, face width $20 \mathrm{~mm}$ and gear ratio 1:1. The light areas in contour plots in the case of load sharing ratio 33:67 and 45:55 enlarge successively with load. These results agree well with the tooth contact pattern that the area where paint is peeled off enlarges with increasing load. On the contrary, for load sharing ratio 50:50 the area having light color does not enlarge with load. However when the applied load become larger than the trigger one, all of the area in the contour plot become light area that mean paint on the tooth surface is almost completely peeled off. From these results, it can be concluded that using the load sharing ratio 33:67 or 45:55 in calculation is more proper than the load sharing ratio 50:50 used in the former calculation.

Figure 5 shows the comparison between contour plots of load distribution of the helical gear tooth surfaces determined by Niemann and Richter method and the photos of tooth contact patterns. The helical gear in this example has 30 teeth. The other parameters are normal module 2.5 , pressure angle $25^{\circ}$, helix angle $33.5^{\circ}$, face width $30 \mathrm{~mm}$ and the gear ratio $1: 1$. The area having light color occurs at the center of gear tooth surface and enlarges to full tooth area at high load. These results agree well with the tooth contact patterns obtained from experiments. This means that the method used to calculate load distribution here is more suitable than the former assumption that load is uniformly distributed along the line of contact. 


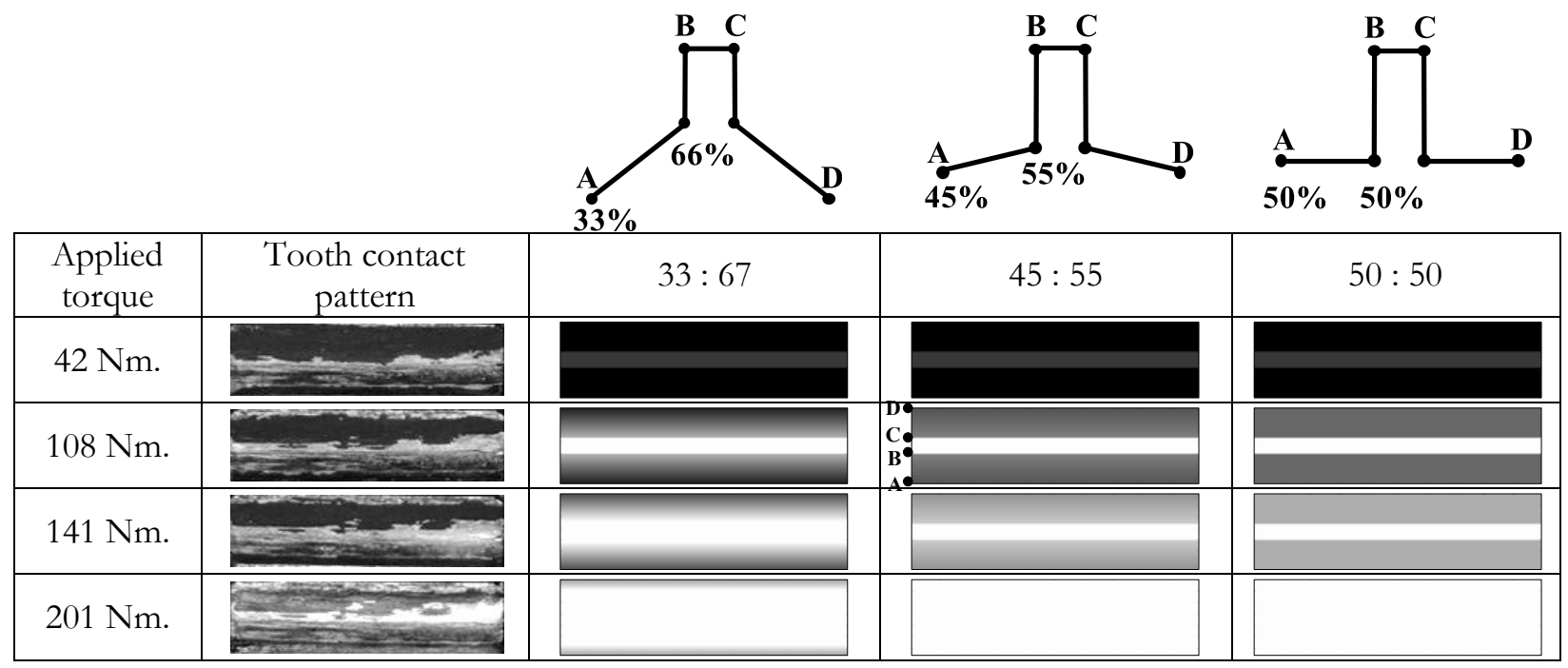

Fig. 4. Load distributions on the spur gear tooth surfaces.

\begin{tabular}{|c|c|c|}
\hline Applied torque & Tooth contact pattern & Niemann and Richter \\
\hline $61 \mathrm{Nm}$. & 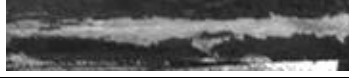 & \\
\hline $115 \mathrm{Nm}$. & & \\
\hline $162 \mathrm{Nm}$. & 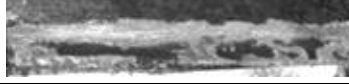 & \\
\hline $237 \mathrm{Nm}$. & 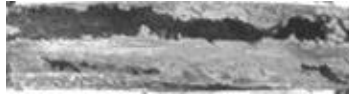 & \\
\hline
\end{tabular}

Fig. 5. Load distributions on the helical gear tooth surfaces.

\section{Calculation process}

The process to estimate the sliding loss by the model with load distribution pattern on gear tooth surface is shown in Fig.6. The details of each step can be described as follows:

\section{Input data}

For the first step, the necessary data are input. The data comprise the gear parameters that are module, number of teeth, pressure angle, helix angle, face width, and gear ratio, the operating conditions that are applied load and speed. The other data necessary for calculation such as the viscosity of the lubricant are also input in this step.

\section{Calculate length of contact}

In this step, the number of tooth pairs meshing at any specific meshing position is determined. For the spur gear the number of meshing pair is one or two, but for the helical gear the meshing pair is probable to be one, two, three or larger value depended on the gear parameters. Once the meshing position is specified, the length of contact of each tooth pair on the plane of action can be calculated, and the total length of contact can also be obtained by combining the contact length of each tooth pair together. 


\section{Calculate load distribution and load sharing}

For the spur gear, when the single tooth pair is mating, total load is applied to the meshing tooth. On the other hand when double teeth are meshing, loads acting on the gear tooth surfaces are shared depended on the load sharing ratio. Load is also uniformly distributed along the line of contact in this case. For the helical gear, load distribution at the specific meshing position of each tooth pair can be calculated from Eq. (4).

\section{Calculate friction coefficient}

Load distribution obtained in the former step is used in friction coefficient calculation. In this work the friction coefficient formula proposed by Benedict and Kelly [2] is used as shown in equation:

$$
\mu=0.0127\left[\frac{50}{50-S}\right] \log _{10}\left[\frac{3.17(10)^{8} W}{v V_{S} V_{r}^{2}}\right],
$$

where $S$ is the surface finish parameter, $W$ is the unit normal load, $v$ is dynamic viscosity of the lubricant, $V_{S}$ is the relative surface sliding velocity and $V_{r}$ is the sum of the rolling velocities.

\section{Calculate sliding loss ratio (single tooth meshing)}

After all related parameters are known, the sliding loss ratio during single tooth meshing can be calculated. For the spur gear the calculation can be done directly by Eq. (2), but for the helical gear it must be modeled as many thin spur gears aligned slantwise along with the base helix angle. The further calculation is the same as the description in section 2 and in the ref [9].

\section{Calculate total sliding loss ratio}

The concept of total sliding loss calculation here is similar to the former calculation, but in the former one, the assumption that load is uniformly distributed along the line of contact was used therefore the total sliding loss ratio can be calculated by directly averaging the sliding loss ratio of all gear teeth meshing simultaneously. For this improved method, due to the non-uniform load distribution, sliding loss ratios of each tooth pair or each section are weighted averaged depended on the amount of load distributed on that tooth or that section.

\section{Calculate average sliding loss ratio and sliding loss}

The sliding loss ratio calculated in the $6^{\text {th }}$ step is time varying. To obtain the representative value of the sliding loss ratio, average sliding loss ratio is calculated. The sliding loss of the gear pair can be calculated further by multiplying the input power by the average sliding loss ratio. The details of calculation are the same as that written in the ref [9]. 


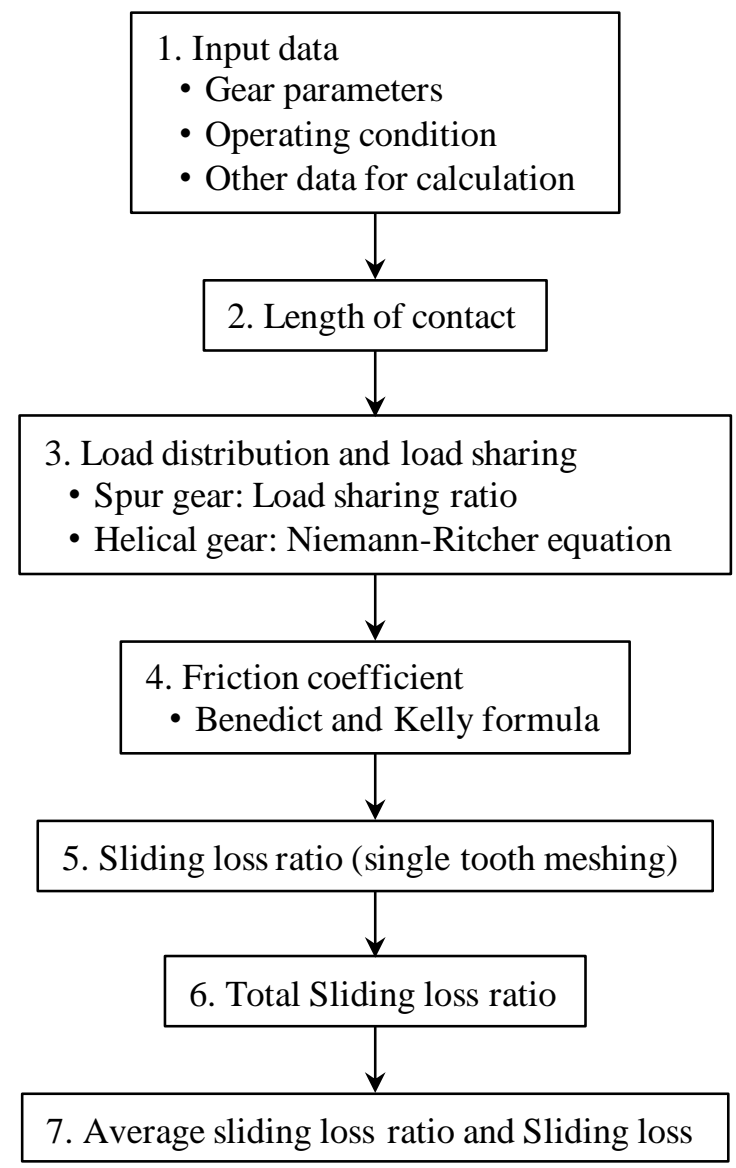

Fig. 6. Diagram of calculation process.

\section{Experiment and Verification}

\subsection{Apparatus}

To verify the sliding loss model, some experiments were done with the back-to-back gear test rig as shown in Fig. 7. This apparatus is the same as that was used in the ref. [10]. This type of the test rig does not have the output power. The input power is applied to compensate various kinds of power loss in the system, in other words the input power represents the power loss in the system. This gear test rig is driven via a belt by a 3 phase motor that its speed is controlled by an inverter. The input torque is measured by a torque transducer, and the shaft rotational speed is measured by a tachometer. Measured signals are amplified and collected by DAQ system that connects to a PC. With these measurements, the input power can be calculated.

Torque is able to apply into the system by ballasting to twist the shafts at one side of a loading coupling to generate the compressive force at the gear tooth surface. After that the twisted shafts are fixed together by the loading coupling. The applied torque is measured by 4-strian gauges attached at the connecting shaft between gearboxes. The lubricant used here was $80 \mathrm{~W} 90$ gear oil that its temperature is controlled at around $70^{\circ} \mathrm{C}$ to control the viscosity.

Because the measured input power represents the total power loss of the system, to separate the sliding loss from the total power loss, two sets of the experiments were done as same as the method described in the ref. [10]. Two sets of the experiments are the experiments with applied load and experiments without load. In the case of experiment without load, the spin power loss is obtained. The load dependent bearing loss can also be determined by the method proposed by Harris [22]. By subtracting the spin power loss and the dependent bearing loss from the total power loss measured from the experiment with applied load, the gear sliding loss can be determined. 


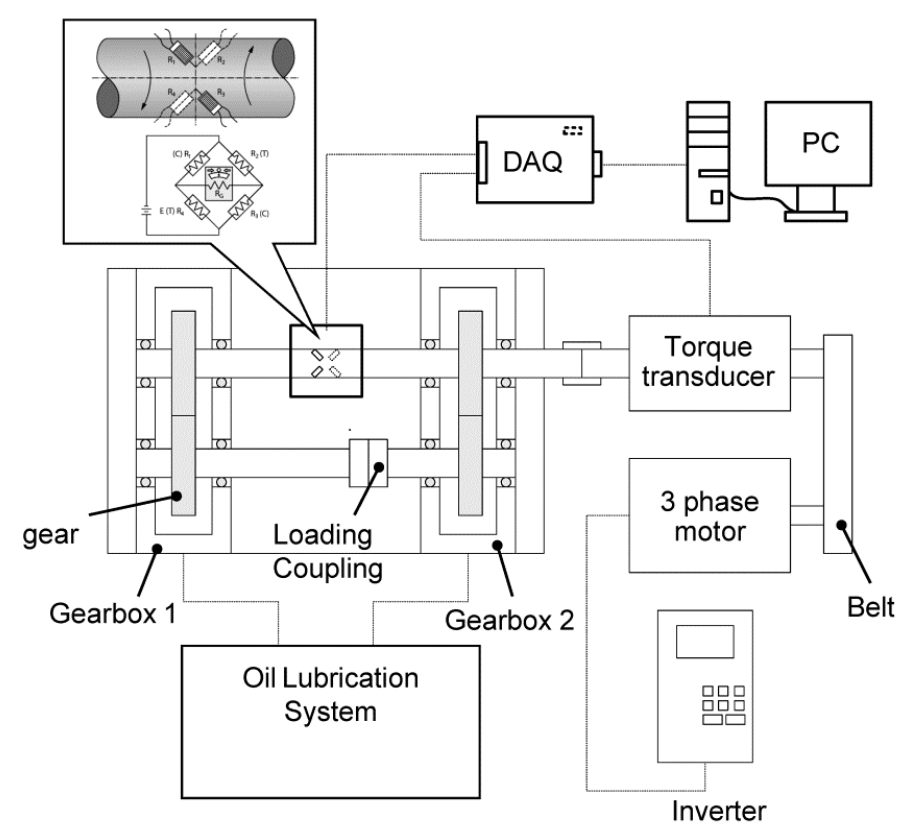

Fig. 7. Back-to-back gear test rig [10].

\subsection{Gear Parameters and Operating Conditions}

Parameters of the test gears and operating conditions are shown in Table 1. There are 3 gear sets used in the experiments that are spur gear S1 and helical gear $\mathrm{H} 1$ and $\mathrm{H} 2$. All of the gear pairs have the same gear ratio $1: 1$ and the same center distance. The helix angles are varies from $0^{\circ}$ for the spur gear to $22^{\circ}$ and $33.5^{\circ}$ degree for the helical gears. Experiments were done with 5 values of applied torque from $0 \mathrm{Nm}$ to about $250 \mathrm{Nm}$. The toque $0-3 \mathrm{Nm}$ represents the experiment without load. The rotational speed of the driving shaft is set at $2000 \mathrm{rpm}$.

Table 1. Gear parameters and operating conditions.

\begin{tabular}{llll}
\hline Parameters & Gear set & & S1 \\
& H1 & H2 & 30 \\
Number of teeth & 30 & 30 & 3 \\
Transverse module, $\mathrm{m}_{\mathrm{t}}(\mathrm{mm})$ & 2.998 & 2.966 & 20 \\
Transverse pressure angle, $\boldsymbol{\alpha}_{\mathrm{t}}(\mathrm{deg})$ & 20 & 20 & 0 \\
Helix angle, $\Psi(\mathrm{deg})$ & 33.5 & 22 & 20 \\
Face width $(\mathrm{mm})$ & 20 & 20 & 0.70 \\
Surface roughness $(\mu \mathrm{m})$ & 0.65 & 0.68 & \\
Applied torque $(\mathrm{Nm})$ & $0-3,10-50,51-100,101-150,151-200,201-250$ \\
Rotational speed $(\mathrm{rpm})$ & 2000 & & \\
\hline
\end{tabular}

\subsection{Experimental Results and Discussions}

Figure 8 shows the sliding loss ratio of the test gears that have the different helix angle. From the experimental results shown in the left graph, the helical gear $\mathrm{H} 1$ that has helix angle $33.5^{\circ}$ has larger sliding loss than the helical gear $\mathrm{H} 2$ that has helix angle $22^{\circ}$ and the spur gear S1 respectively. Comparing to the estimated results shown in the middle figure for the improved model and the right one for the former model, it is found that the former one estimates the sliding loss of the helical gear $\mathrm{H} 2$ more than helical gear $\mathrm{H} 1$ that does not agree with the experimental results, whereas the improved model estimates the 
sliding loss of the helical gear H1 higher than those of helical gear H2 and spur gear S1 respectively that well conform with the experiments. The magnitudes of the sliding losses estimated from the improved model are also closer to the measured sliding loss than the estimations from the former model.

The causes of the difference between the sliding loss estimated from the former model and the improved model can be explained by the length of contact and the load distribution on the gear tooth surface as shown in Fig. 9. The horizontal axis in Fig. 9(a) and (b) is meshing position from start meshing point to the finish meshing point. In the former estimation, load is considered to be distributed uniformly along the line of contact. The helical gear $\mathrm{H} 1$ that has helix angle $33.5^{\circ}$ has total length of contact longer than the helical gear $\mathrm{H} 2$ that has helix angle $22^{\circ}$ as shown in Fig. 9(a), hence the load distribution and the estimated sliding loss of the helical gear $\mathrm{H} 1$ in the former model are smaller than that of the helical gear $\mathrm{H} 2$ In the improved model the load distribution is calculated by the method of Niemann and Richter, and the load distributions of both helical gears are shown in Fig. 9(b). For the helical gear H1, larger load is distributed at the tooth root and tooth tip where the sliding velocity is very high, hence the sliding loss of this gear pair is large. On the other hand for the helical gear H2, the load is largely distributed at the center of the gear tooth surface where the sliding velocity is very low, but small distributed at the tooth root and tip where the sliding velocity is large. With this reason the estimated sliding loss of the helical gear H2 is smaller than the sliding loss of the helical gear H1 in the improved model.

The results in the case of the spur gear S1 estimated with various load sharing ratios are shown in Fig. 10. The solid line in Fig. 10 shows the experimental results, and the other dash lines express the estimations with various load sharing ratios. From the figure, the result estimated with load sharing ratio 50:50 that is used in the former model has larger sliding loss than that estimated with load sharing ratio 45:55 and 33:67 respectively due to the larger load distribution at the tooth root and tooth tip as shown in Fig. 3. At low load conditions, all of estimations are agree well with the experimental result, but at largest load the estimation with load sharing ratio 33:67 is closest to the experimental result.
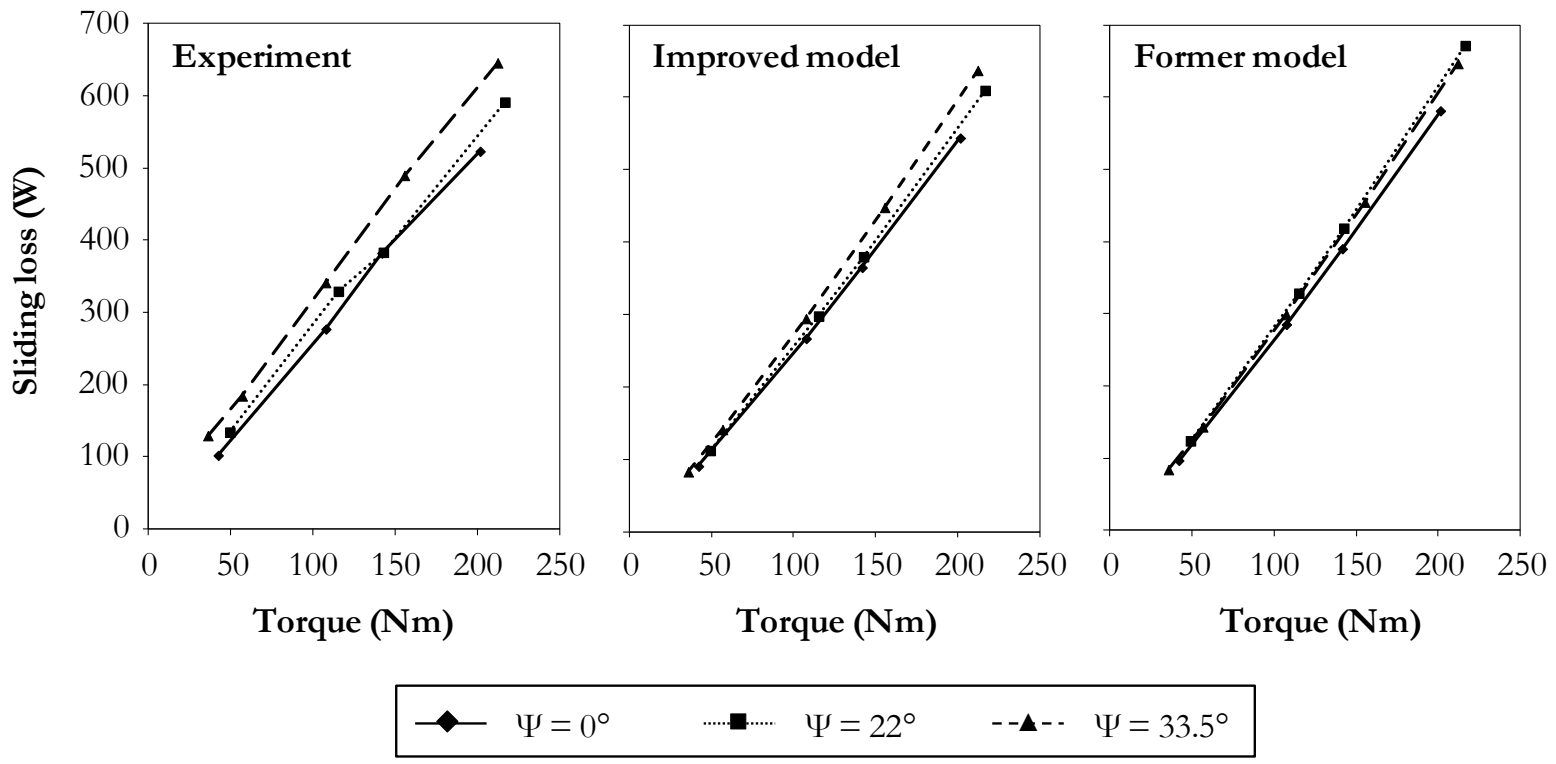

Fig. 8. Sliding losses of test gears with various helix angles. 


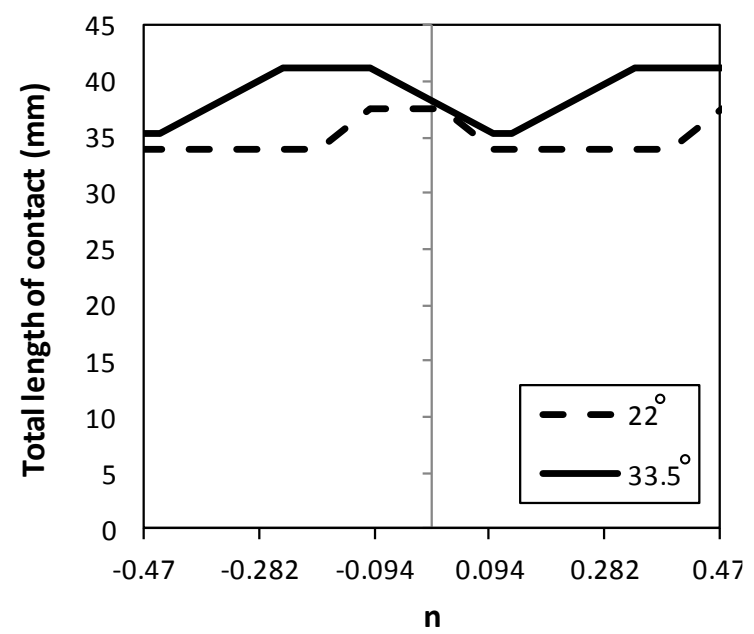

(a)

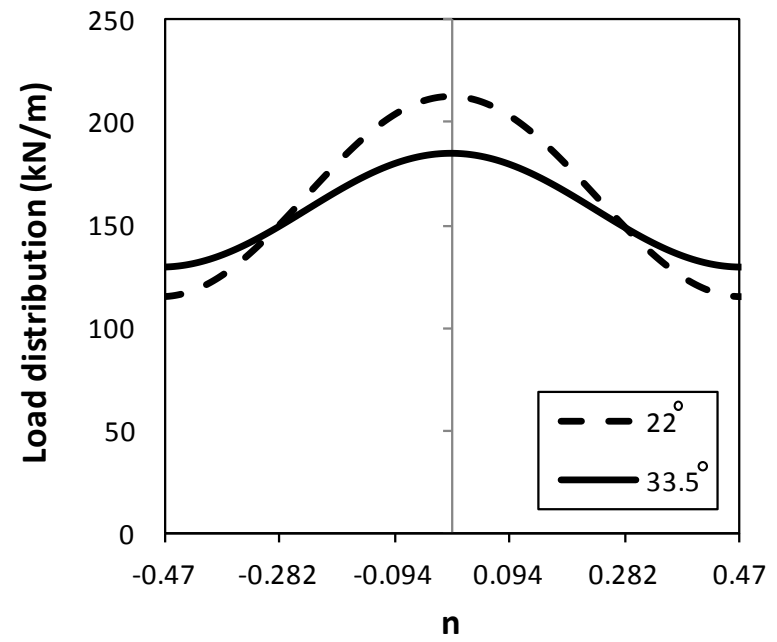

(b)

Fig. 9. Length of contacts and load distributions of the helical gear H1 (helix angle $33.5^{\circ}$ ) and the helical gear $\mathrm{H} 2$ (helix angle $22^{\circ}$ ).

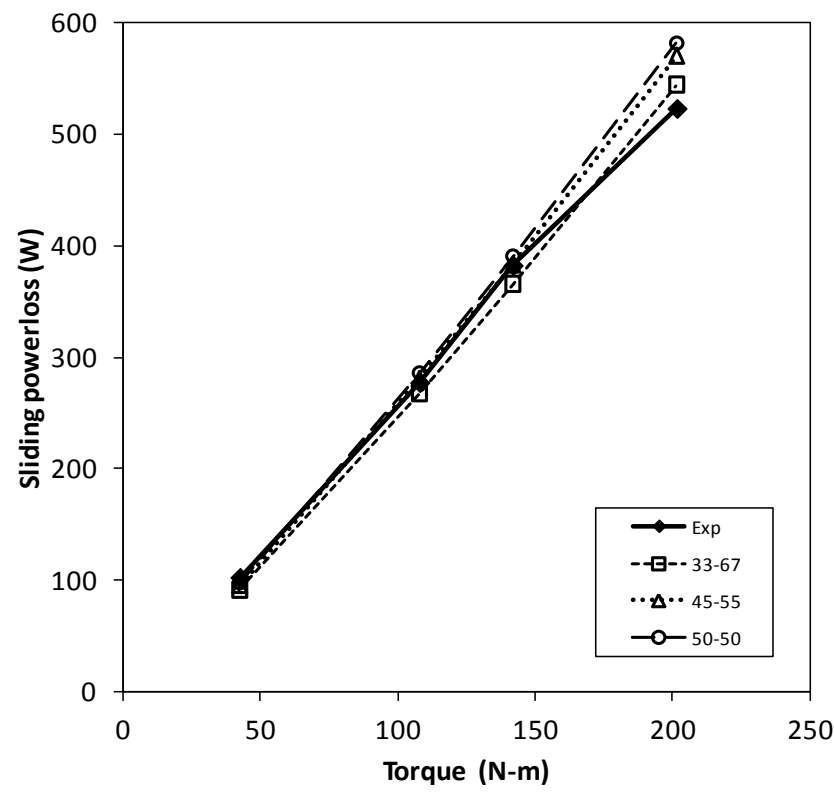

Fig. 10. Sliding losses of the spur gear pair estimated with different load sharing ratios.

\section{Verification with Other Experimental Results}

The estimated results were also verified with the results reported by Vaidyanathan [23]. Vaidyanathan did the experiments by the back-to-back gear box system. The parameters of the gear set used in his work and the operating conditions are shown in Table 2. The parameters of gear set $\mathrm{A}$ and gear set $\mathrm{C}$ are almost the same except the helix angle that the gear set $\mathrm{A}$ is a spur gear but the gear set $\mathrm{C}$ is a helical gear having helix angle $30^{\circ}$. The gear set $\mathrm{B}$ and $\mathrm{C}$ also have the similar gear parameters except the transverse pressure angle that is changed from $29.3^{\circ}$ in gear B to $25.8^{\circ}$ in gear C. The effect of changing both helix angle and pressure angle can also be studied by comparing the results of gear set $\mathrm{A}$ and gear set $\mathrm{B}$.

Figure 11 shows the comparison of the estimated results from the former model and the improved model to some of the results reported by Vaidyanathan. Overall, the sliding losses estimated by the improved model have lower amplitude than the results estimated by the former models, and also closer to 
the experimental results. Furthermore both the former model and the improved model can estimated the effect of changing either helix angle or pressure angle on the sliding loss correctly. The helical gear set $\mathrm{C}$ that has larger helix angle than the gear set $\mathrm{A}$ also has higher sliding loss. The gear set $\mathrm{B}$ having larger pressure angle has lower sliding loss than the gear set $\mathrm{C}$. However when comparing the gear set $\mathrm{A}$ and gear set $\mathrm{B}$ that both helix angle and pressure angle are changed together, it is obvious that the former model cannot estimate the trend of sliding loss correctly. The former model estimates the sliding loss of gear set $\mathrm{A}$ almost the same with the gear set $\mathrm{B}$, while from the experiments the gear set $\mathrm{A}$ has higher sliding loss than the gear set B. On the contrary the improved model is able to estimate the sliding loss in this case properly.

Table 2. Gear parameters and operating conditions of Vaidyanathan's work [23].

\begin{tabular}{llll}
\hline Parameters & Gear set & \\
& A & B & C \\
\hline Number of teeth & 23 & 23 & 23 \\
Transverse module, $\mathrm{m}_{\mathrm{t}}(\mathrm{mm})$ & 3.95 & 3.98 & 3.95 \\
Transverse pressure angle, $\alpha_{\mathrm{t}}(\mathrm{deg})$ & 25 & 29.3 & 25.8 \\
Helix angle, $\Psi(\mathrm{deg})$ & 0 & 30 & 30 \\
Face width $(\mathrm{mm})$ & 26.67 & 26.67 & 26.67 \\
Absolute Viscosity $(\mathrm{cP})$ & 6.732 & 6.732 & 6.732 \\
Surface roughness $(\mu \mathrm{m})$ & 0.37 & 0.28 & 0.32 \\
Load operation condition $(\mathrm{Nm})$ & $140,239,413,546$ & \\
Speed operation condition $(\mathrm{rpm})$ & $2000,4000,6000$ & \\
\hline
\end{tabular}
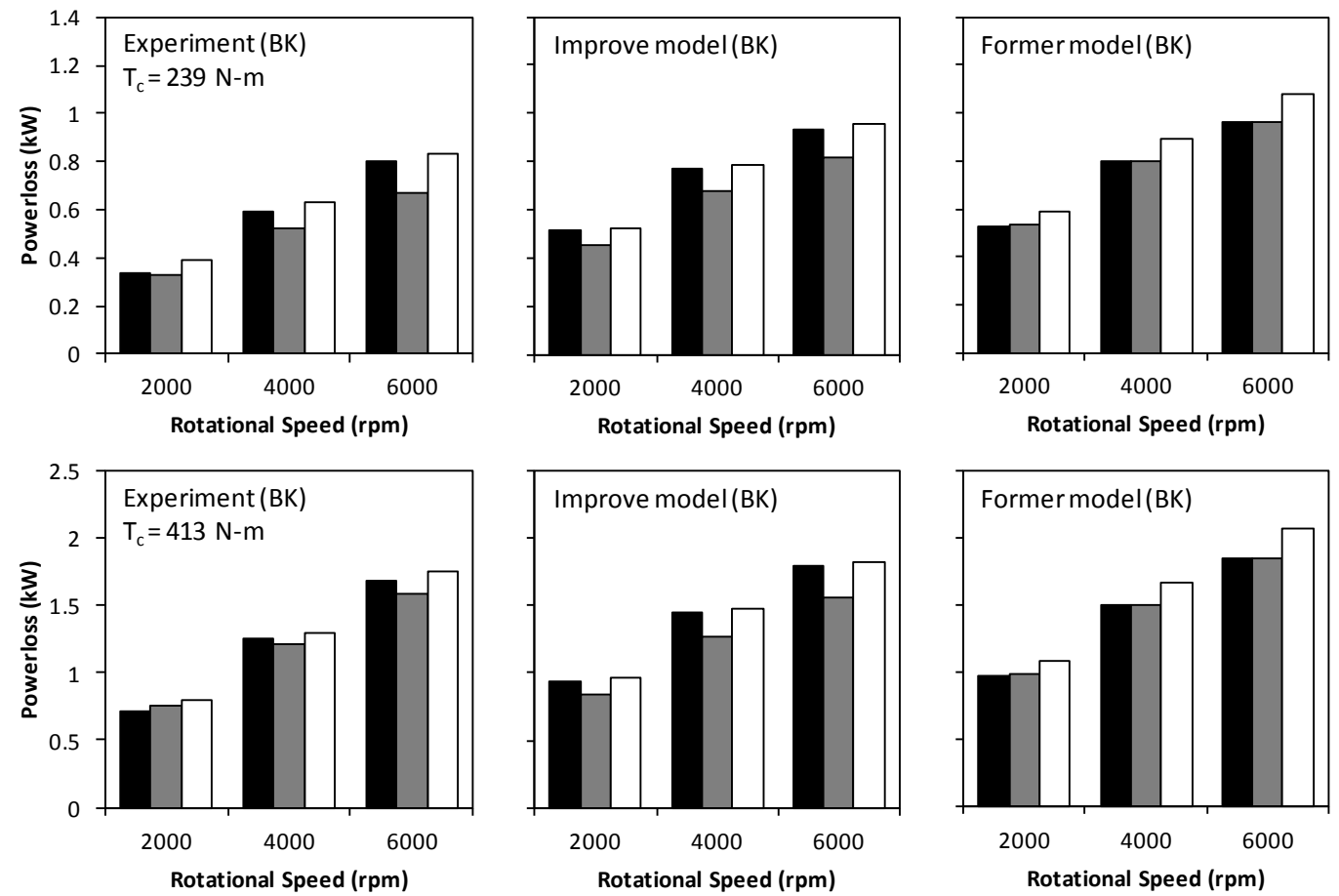

$\boldsymbol{\square} \Phi \mathrm{t}=25^{\circ}, \Psi=0^{\circ}$ (A) $\square \Phi \mathrm{t}=29.3^{\circ}, \Psi=30^{\circ}$ (B) $\square \Phi \mathrm{t}=25.8^{\circ}, \Psi=30^{\circ}$ (C)

Fig. 11. The effects of gear parameters on the sliding loss [23].

The estimated results are also compared to the other experimental results in the ref. [23] as shown in Fig. 12. The vertical axes in these graphs show the sliding losses from Vaidyanathan's experiments, on the other hand the horizontal axes are the sliding losses estimated from the improved model and the former model. One data point is the sliding loss of a particular gear set operated at a specific condition corresponding with the data shown in Table 2. If the estimated sliding loss is close to the experimental 
results, the data point will be located close to the 45 -degree line. From the results, it is obvious that the data points in the case of improved model located closer to the 45-degree line than the former model. The correlation $\left(\mathrm{R}^{2}\right)$ of the data and the 45 -degree line for the improved model is 0.91 closer to 1 than the value of the former model that is 1.2. These conclude that the improved model can estimate the sliding losses better than the former model.
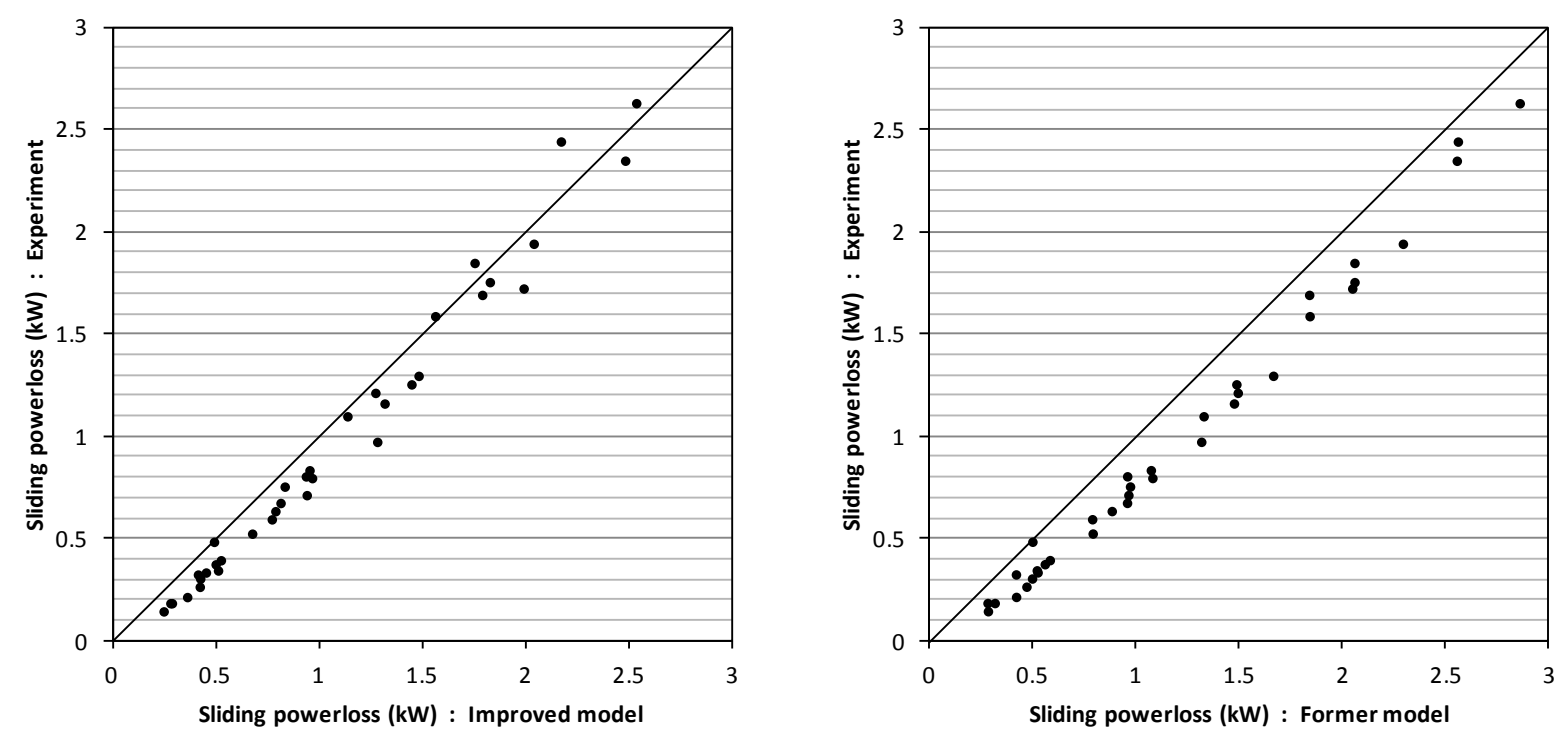

Fig. 12. Comparison of the estimated results to the results in the ref. [23].

\section{Conclusions}

The method to estimate sliding loss of a spur and a helical gear pair with load distribution pattern is proposed in this paper. The load distribution of the spur gear pair is considered to be distributed uniformly along the line of contact, and the load sharing ratio during double teeth meshing is set to be 33:67 percent or 45:55 percent. For the helical gear pair the formula proposed by Niemann-Richter is used in load distribution calculation. The contour plots of the load distribution calculated by above methods conform to the tooth contact patterns obtained from the experiment. This assures that the load distribution used in calculation is applicable.

The sliding losses estimated from the improved method are compared to the sliding losses calculated from the former method and sliding loss measured from the experiments. The results show that the presented method can estimate the effect of helix angle and pressure angle on the sliding loss properly, whereas the former method cannot. Moreover the magnitudes of the sliding losses estimated from the improved model are closer to the experimental results than the former method. These results verify the capability of this method for estimate the sliding loss.

\section{Acknowledgements}

This work was financially supported by the Department of Mechanical Engineering, Chulalongkorn University.

\section{References}

[1] Y. Michlin and V. Myunster, "Determination of power loss in gear transmission with rolling and sliding friction incoporated," Mech. Mach. Theory, vol. 37, no. 2, pp. 167-174, 2002.

[2] G. H. Benedict and B. W. Kelly, "Instantaneous coefficients of gear tooth friction," ASLE Trans, vol. 4, no. 1, pp. 59-70, 1961.

[3] Y. N. Drozdov and Y. A. Gavrikov, "Friction and scoring under the conditions of simultaneous rolling and sliding of bodies," Wear, vol. 11, no. 4, pp. 291-302, 1968. 
[4] ISO TC 60, DTR 13989.

[5] Y. A. Misharin, "Influence of the friction condition on the magnitude of the friction coefficient in the case of rollers with sliding," in Proc. Int. Conf. on Gearing, Inst. Mech. Eng., London, 1958, pp. 159-164.

[6] J. P. O'Donoghue and A. Cameron, "Friction and temperature in rolling sliding contacts," ASLE Trans, vol. 9, pp. 186-194, 1966.

[7] N. E. Anderson and S. H. Lowenthal, "Effect of geometry and operating conditions on spur gear system power loss," J. Mech. Des.-T ASME, vol. 103, pp. 151-159, Jan. 1981.

[8] Y. Terauchi, K. Nagamura, and K. Ikejo, "Study on friction loss of internal gear drives (influence of pinion surface finishing, gear speed and torque)," JSME Int. J. III, vol. 34, no. 1, pp. 106-113, 1991.

[9] C. Ratanasumawong, P. Asawapichayachot, S. Phongsupasamit, H. Houjoh, and S. Matsumura, "Estimation of sliding loss in a parallel-axis gear pair," J. Adv. Mech. Des. Syst., vol. 6, no. 1, pp. 88-103, 2012.

[10] C. Yenti, S. Phongsupasamit, and C. Ratanasumawong, "Analytical and experimental investigation of parameters affecting sliding loss in a spur gear pair," Engineering Journal, vol. 17, no. 1, pp. 79-93, 2013.

[11] H. Xu, A. Kahraman, N. E. Anderson, and D. G. Maddock, "Prediction of mechanical efficiency of parallel axis gear pairs," J. Mech. Des.-T ASME, vol. 129, pp. 58-68, Jan. 2007.

[12] Y. Diab, F. Ville, and P. Velex, "Prediction of power losses due to tooth friction in gears," Tribol. Trans., vol. 49, no. 2, pp. 260-270, Jul. 2006.

[13] P. Asawapichayachot, "Improvement of a mathematical model and experiment for estimation of sliding loss in helical gear transmission," (in Thai) M.S. thesis, Mech Eng Dept., Chulalongkorn Univ., Bangkok, 2011.

[14] J. Phraeknanthoe, N. Ponchai, and C. Ratanasumawong, "Utilization of tooth contact pattern in a gear meshing model for estimation of sliding loss in a parallel-axis gear pair," Applied Mechanics and Materials, vol. 619, pp. 68-72, 2014.

[15] J. I. Pedrero, M. Pleguezuelos, M. Artés, and J. A. Antona, "Load distribution model along the line of contact for involute external gears," Mech. Mach. Theory, vol. 45, no. 5, pp. 780-794, 2010.

[16] M. Ristivojević, T. Lazović, and A. Vencl, "Studying the load carrying capacity of spur gear tooth flanks," Mech. Mach. Theory, vol. 59, pp. 125-137, 2013.

[17] V. Spitas, G. A. Papadopoulos, C. Spitas, and T. Costopoulos, "Experimental Investigation of Load Sharing in Multiple Gear Tooth Contact Using the Stress-Optical Method of Caustics," Strain, vol. 47, pp. e227-e233, 2011.

[18] S. Li, "Effect of addendum on contact strength, bending strength and basic performance parameters of a pair of spur gears," Mech. Mach. Theory, vol. 43, no. 12, pp. 1557-1584, 2008.

[19] G. A. Niemann, "Spur and helical gears, design and calculation," in Machine Elements: Design and Calculation in Mechanical Engineering Vol. II GEARS. India: Springer-Verlag, 1978, sec. 22.3, pp. 103-112.

[20] L. Vedmar, "On the design of external involute gears," Lund Institute of Technology, 1981.

[21] Q. Wang and Y. Zhang, "A model for analyzing stiffness and stress in a helical gear pair with tooth profile errors," J. Vib, Control, vol. 23, no. 2, pp. 272-289, 2017.

[22] T. A. Harris and M. N. Kotzalas, Rolling Bearing Analysis_Essential Concepts of Bearing Technology. Boca Raton, CRC Press, 2007.

[23] A. Vaidyanathan, "An Experimental Investigation of Helical Gear Efficiency," doctoral dissertation, Mechanical Engineering, The Ohio State Univ., Ohio, 2009. 